\title{
Designing an Optimal Pattern of Assessing Native and Non-Native Managers' Performance in Hormozgan Province, Iran
}

\author{
Tayeb Dehghani ${ }^{1}$, Serajaldin Mohebbi ${ }^{2 *}$, Mehdi Bagheri ${ }^{3}$ \\ 1,2*Department of Management, Qeshm Branch, Islamic Azad University, Qeshm, \\ Iran \\ ${ }^{3}$ Department of Management, College of Accounting \& Management, Bandar abbas Branch, Islamic Azad \\ University, Bandar Abbas, Iran
}

\section{Keywords:}

Native and non-native managers, Performance assessment, 360degree feedback, Analytic network process

\section{Received}

06 August 2020

Received in revised form

15 October 2020

Accepted

23 October 2020

*Correspondence:

mohebi.abcd@gmail.com

\begin{abstract}
Nowadays, the issue of public sector managers' responsiveness to their actions in the new managerial environment is addressed more intensely. Therefore, in the modern attitude, assessing managers' performance as a framework for implementing strategies and policies, achieving organizational goals, and their responsiveness to beneficiaries and the society is considered. This study aims to develop an optimal pattern to assess native and non-native managers' performance in terms of four aspects of human, perceptual, and technical skills as well as personal traits and measure their performance through the combination of $360-$ degree feedback and analytic network process. The statistical population consists of two groups of native and non-native managers in key posts in Hormozgan province. The required samples, who were selected through proportional stratified random sampling, for the groups of native and non-native managers are respectively estimated to be 31 and 23 . The indices of performance assessment were extracted through the meta-synthesis method and validated using the Delphi technique and experts' opinions. By combining 360-degree feedback and analytic network process, native and non-native managers were appropriately ranked, which this ranking can be applied to administrative agencies of Hormozgan Province.
\end{abstract}

The term "survival and demise of the government" is regarded as one of the significant and noteworthy issues in political philosophy and managers' performance in the political system (Tripathy, Ray, \& Sahu, 2011). Managers' appropriate behaviour plays a leading role in strengthening the bases of the government and its survival (Bititci, Garengo, Dörfler, \& Nudurupati, 
2012). This aim is achievable only through selecting competent people, providing political education, and evaluating their performance frequently, since position and power may corrupt them or change their nature (Tangen, 2004). According to the principle that nowadays managers' responsiveness is increasingly regarded as a significant concern in the literature of governance, growing favourites in terms of responsiveness are mostly explained through the emergence of new patterns of administration (governance) which have challenged the traditional mechanisms of governance (Sharma, Bhagwat, \& Dangayach, 2005). Therefore, assessing the performance of public sector managers is defined as a systematic attempt to measure their responsiveness to people's needs and the government's ability to fulfil these needs (Halachmi, 1999). Measuring managers' performance adapts professional capabilities, behavioural characteristics, and their results to organizational strategies to the greatest extent (Huang, Tong, Ye, \& Li, 2019) so that their actions will be aligned with macro-politics of any society (Folan \& Browne, 2005). Therefore, the present research attempts to answer the following question: what is the optimal pattern of assessing native and non-native managers' performance in key posts in Hormozgan Province?

\section{Literature Review}

The issue of responsiveness in the private sector is always attractive, and it has been attempted to create appropriate structures and methods to make it happen. However, in the public sector, responsiveness gains greater importance due to issues related to the public interest (Aschbacher \& Herman, 1991). By changing the quasi-paradigms of administration and the emergence of new methods of governance such as modern governmental management and modern public services, the issue of public sector managers' responsiveness to their actions in the new governance environment will be addressed more intensely (Moxham, 2009). Considerable complexities of this modern style such as the attempt and role of management in protecting the public interest, reducing unnecessary bureaucracy, emphasizing the outputs, and developing competition confirm the need for a consensus on using practical methods and models of assessing governance in the public sector (Franco-Santos, Lucianetti, \& Bourne, 2012). Therefore, in the modern attitude, assessing managers' performance as a framework for implementing strategies and policies, achieving organizational goals, and their responsiveness to beneficiaries and the society is considered (Sanderson, 2002), which its primary goal is to enhance abilities and competencies and train managers who are being assessed (Hall, 2008).

One of the fundamental issues in the studies related to the productivity of public sector organizations is to select and employ efficient managers and measure their performance in the governance environment of countries (Henri, 2006). Therefore, progressing and producing high organizational performance and facing the surrounding turbulent environment requires a mechanism to confirm the organization's forward movement through the constant assessment of public sector managers (Modell, 2001). Performance assessment is one of the essential issues and most severe duties in human resource management. Performance assessment aims to adapt to standards, develop a relationship with beneficiaries and manage them effectively, and fulfil the society's need efficiently (Wang, Oh, Courtright, \& Colbert, 2011). In addition, due to social and cultural revolutions, novel and important issues such as being a native or non-native manager have emerged. Being a native or non-native manager has been the topic of a large number of research in the world, and many researchers have attempted to discover its relationship with other variables (Kim \& Oh, 2002). Some researchers believe that the nature of non-native managers' duties and 
functions is complicated due to cultural barriers (Sharifi, 2010). For example, in countries whose economic bases consist of multi-national companies, the issue of non-native managers' performance is regarded as a significant challenge and researchers have attempted to study its various aspects (Cavalluzzo \& Ittner, 2003). The socio-cultural environment creates challenges when managers interact with the workforce in the organization and serve customers.

Furthermore, the socio-cultural environment of any society determines values, norms, personal beliefs, attitudes, and preferences (Heinrich, 2002). Since the activities of an organization depend on the behaviour and conception of people who live in that society, organizational behaviour is deeply influenced by the socio-cultural environment that the organization works in it (Kloot \& Martin, 2000). Therefore, the mentioned environment is of great importance, especially for effectively managing human resources in organizations. Since the underlying factors of culture and traditional values influence the attitude and performance of managers and the latter is highly adaptable to the values of the society, it is appropriate to recruit managers according to the general policies of the administrative system, i.e. recruiting able, committed, and competent workforce and avoiding narrow-mindedness as well as subjective and unprofessional attitudes in the public sector based on native selection. Furthermore, it is proper to differentiate between skill level and geographical area and recruit managers without considering cultural and traditional elements of societies.

Some previous studies that have examined the subject of the present study from different angles have reached the results that we have briefly mentioned. For example, in an article entitled "Employee Evaluation by Hierarchical Analysis," Taylor et al. (1990) review and provide solutions to two major problems in conventional employee performance appraisal methods. The authors consider the use of hierarchical analysis as an effective and convenient method for evaluating personnel and discuss the classification of indicators and options to reduce the number of comparisons necessary (Takagi,1991). Through the correct application of group decision-making techniques, the authors believe that multi-criteria decision-making problems were solved (Mikolajczyk \& Schemid, 2005). Research has also shown that the adaptation of non-native managers in terms of job performance with native employees is different because spatial attachment is generally referred to as nodes; the emotions that people develop with their place of residence are specified (Ward \& Kennedy, 2001). Attachment and spatial identity are higher in towns than in cities and are positively related to cities' size and the length of time a person has lived in them (Ward, Bochner, \& Furnham, 2001). They affect critical social relationships (Zhou Jindal-Snape, Topping, \& Todman, 2008) and is one of the strongest predictors of spatial identity (Smith \& Khawaja, 2011). The importance of spatial attachment is that it can lead to a clear perspective in participatory management and create an open and inclusive social space. The social foundation of emotional relationships is also related to the location and insights of individuals' local relationships (Rienties et al., 2012).

Some other researchers have examined the role of various stressors, the role of situational stressors, and social support as predictors of success for non-native managers (Brown \& Pehrson, 2019). In these studies, it has been found that the dimension of work-family interaction in nonnative employees is higher than the average of the community. In this way, it creates problems in balancing work and family responsibilities and creates grounds for incompatibility. However, a significant gap is the lack of attention to the role of these employees (Kelly, 2012). 


\section{Selecting the Method of Performance Assessment}

Unfortunately, most assessment systems being used in organizations have been designed weakly and inappropriately (Melnyk, Bititci, Platts, Tobias, \& Andersen, 2014). Deciding what kind of performance must be assessed and how it must be measured is a function of four indices: credit, validity, avoiding orientation and prejudice and making practical (Krishna, Mohan, Murthy, \& Rao, 2002). Factors that are useful in determining the type of assessment system include the size of the organization, its dynamics, different levels in the hierarchy, and giving employees some feedback on their performance. By comparing the methods of performance assessment, it is found that each method has some advantages and disadvantages that encourage users to apply them. For deciding to choose the best assessment method, we must answer this question: "the best method to do what?" In a study conducted by Jafari (2009), a framework was presented to choose the appropriate method of performance assessment. In this study, nine performance assessment methods were compared and ranked according to the following indices: assessment of educational needs, compliance with rules, encouraging employees to become perfect, comparability, the cost of the method, and having no error. According to Table 1, the methods of management by objectives and 360-degree feedback are at the top; if human resource managers use each of these methods to assess employees' performance, they will achieve similar results (Asgharizadeh, Ehsani, \& Valipour, 2012).

Table 1

Ranking the Methods of Performance Assessment Using the SAW Method

\begin{tabular}{lc}
\hline Methods & Methods grades \\
\hline MBO & .91 \\
360 Degree Feedback & .87 \\
BARS & .82 \\
The checklist & .72 \\
(Forced choice) \& (Ranking) & .66 \\
The eritical incident & .54 \\
The graphic rating scale & .51 \\
The essay & .4 \\
\hline
\end{tabular}

360-degree feedback refers to the process of systematically collecting data on the performance of individuals or their beneficiaries. The method of 360-degree feedback is regarded as one of the modern systems of assessing and developing people especially managers in world's leading organizations which seeks opinions of different beneficiaries in order to provide a more accurate assessment of people's performance and abilities. The answer of "why organizations use 360degree feedback?" lies in the following sentence; the most critical applications of this method include payment (85.6\%), giving feedback (65.1\%), training and development $(64.3 \%)$, employee progression $(45.3 \%)$, human resource planning (43.1\%), retaining and dismissal $(30.3 \%)$, and investigation (17.2\%) (Lawler, 1967). Companies apply 360-degree feedback to employees' career progression and training (93\%) and their assessment (28\%).

\section{The Study}

This study aims to design an optimal model for evaluating the performance of native and nonnative managers of Hormozgan province in critical posts. Therefore, this study addresses the following question:

What indicators should be considered to assess the performance of managers?

What is the weight of managers' performance evaluation indicators? 
What will be the result of performance evaluation based on the 360-degree method and TOPSIS?

\section{Method}

According to Brugal (2005), survey research includes three categories of longitudinal, transverse, and Delphi research. However, survey research is the most general type of social science research based on a survey of those directly involved in the research problem (Jafari, Bourouni, \& Amiri, 2009). In this study, a descriptive survey method has been used. The main stages of the research included defining the main and sub-indicators using a questionnaire and a survey based on the Delphi method and the use of various sources. In the second stage, by asking the experts, the indicators were divided into four categories: individual characteristics, human skills, perceptual skills, technical skills, and the weights of the indicators were calculated. In the third stage, by combining two 360-degree techniques and TOPSIS decision-making techniques, managers will be evaluated and ranked. A researcher-made questionnaire was used to collect the necessary data to measure the performance of native and non-native managers. Experts have validated the dimensions and metrics required to evaluate performance through Delphi. The questionnaire consists of 69 questions that are scaled based on the Likert five-choice spectrum.

\section{Presenting the Model of Managers' Performance Assessment}

Manager's performance has been assessed in terms of four dimensions, and for each dimension, some secondary indices have been defined. Primary indices are explained in detail as follows:

Personal traits: behaviour and personal characteristics (clean appearance, adherence to Islamic ethics, rituals, and behaviour, honesty, being open to criticism, flexibility, oratory, explicit and decisive speech and behaviour, and trustworthiness)

Human skill: person's ability to cooperate, consult or communicate with other people (Verbeeten, 2008) (participation in social activities of the organization, appropriate behaviour towards colleagues and beneficiaries, training, learning, and growing, transfer of knowledge, experience, and skill, active and productive participation in meetings, ability to motivate employees, providing coordination, creating a win-win workplace, and team building).

Perceptual skill: in addition to personal traits, a person has some behavioural characteristics which are affected by the organization (Moynihan \& Pandey, 2005) (having no unnecessary expectations, creativity and innovation, problem-solving, maintaining administrative discipline, ability to predict the consequences of any action, decision-making, having systematic thought, judgment, and keeping secrets).

Technical skill: the ability to use tools, methods, and knowledge required to take action by the person (Verbeeten, 2008) (up-to-date knowledge and information, applying modern technologies, planning, positive work experience, monitoring and controlling, supporting the personnel, speaking foreign languages, organization, ability to set goals, meritocracy, optimal allocation of resources, the power to reward or punish, and risk-taking).

The combination of primary and secondary indices as well as the 360-degree feedback method are presented in the following schematic figure (Figure 1): 


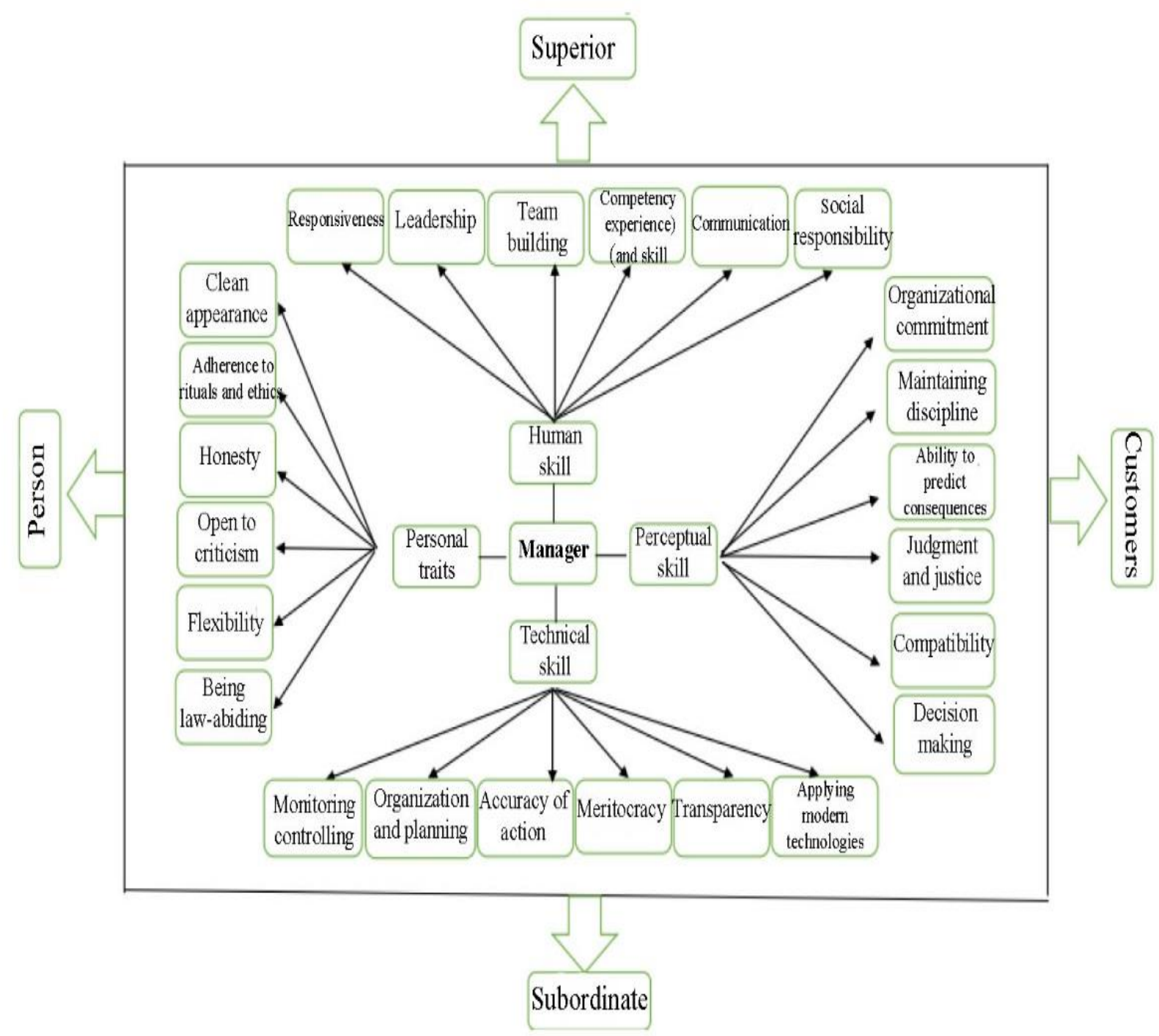

Figure 1 . The combination of primary and secondary indices as well as the 360 -degree feedback method

\section{Statistical Population and Sampling Method}

The statistical population is divided into two groups: The first part (Delphi questionnaire) which its population consists of academic and administrative elites. The second part which its population consists of all the general managers of administrative agencies in Hormozgan Province (63 people).

The sampling method of the present study to measure indices through Delphi technique was snowball sampling. Snowball sampling is a helpful method for qualitative and exploratory studies. According to the latest gathered information about the number of native and non-native managers from Management and Planning Organization of Hormozgan Province, out of 63 general managers, 36 managerial posts (57\%) in this province are occupied by native people. According to the limited statistical population of general managers in administrative agencies (63), Cochran's formula was applied to determine the optimal sample size of this research. The optimal sample size was equal to 54 people based on this formula.

Proportional stratified random sampling was also used to select the samples. In proportional stratified random sampling, individuals of the population are divided into different categories based on their intra-group characteristics and samples are selected from these categories proportionally. The sub-categories of this study who were homogeneous in terms of intra-group characteristics included native and non-native managers. The number of native managers was equal to 36 , and the 
number of non-native managers was 27. In each sub-category, the optimal sample size was selected according to the numbers mentioned above, which was equal to 31 for native managers and 23 for non-native managers. Therefore, in this method, questionnaires are distributed among all the categories of a population proportionally and determining the sample size is of great importance in order to generalize the results.

In 360-degree feedback, it is required to determine an assessing group. The assessing group is selected according to the following conditions: familiarity with the person being assessed, the number of contact with the person being assessed, familiarity with what the person being assessed is doing, people who work with the person being assessed, having sufficient motivation for providing an accurate and valid assessment, having self-confidence and making a fair judgment, accountability, and taking the assessment seriously (de Andrés, García-Lapresta, \& Martínez, 2010).

According to the nature of 360-degree feedback, for each person being assessed, a superior, a client, and a subordinate must be selected. Therefore, since there were 31 native and 23 non-native managers in the role of the person being assessed and according to the fact that each person being assessed can have different roles, this led to adjusting the number of assessors for native and nonnative samples being assessed, which was equal to 120 and 90 respectively. The opinion of assessors about the person being assessed is different. The weight of indices and the experts' opinions about the importance coefficient of each assessor group were collected simultaneously using Delphi method. Accordingly, the weight of the person being assessed in the role of manager, colleague, subordinate, and the person is equal to $37 \%, 22 \%, 24 \%$, and $17 \%$, respectively. The demographic characteristics of the statistical sample revealed that $69 \%$ of the respondents were men, and $31 \%$ were women. In terms of educational level, about $47 \%$ of those evaluators had a bachelor's degree, $41 \%$ had a master's degree, and about $12 \%$ had a doctorate degree. As presented in Table 2, the average management experience of native managers in previous years was about seven years, and their average management experience in the current post was about four years. The average management experience of non-native managers in past years was about six years, and their average management experience in the current position has been nearly two years.

Table 2

Relative Distribution of Native and Non-native Appraisers by Years of Service

\begin{tabular}{llcc}
\hline \multicolumn{1}{c}{ Group } & \multicolumn{1}{c}{ Years of Service } & Average & \\
\hline \multirow{2}{*}{ Native managers } & Management history in previous years & 6.88 & \\
& Management history in the current post & 3.65 & 0.94 \\
\multirow{2}{*}{ Non-native managers } & Management history in previous years & 6.24 & 2.12 \\
& Management history in the current post & 2.04 & 1.26 \\
\hline
\end{tabular}

Due to the nature of 360-degree evaluation, each manager will be evaluated on four sides. As shown in Table 3, for every 54 managers, including the managers themselves in the role of both evaluator and being assessed, there were 54 superiors, subordinates, and clients in the role of evaluator.

Table 3

Relative Distribution of Evaluators

\begin{tabular}{lcc}
\hline Job position & Abundance & Percent \\
\hline person & 54 & 26.7 \\
Client & 54 & 26.7 \\
Superior & 54 & 26.7 \\
Subordinate & 54 & 26.7 \\
Total & 216 & 100 \\
\hline
\end{tabular}




\section{Identifying Indicators}

Evaluating the performance of managers using the TOPSIS method is necessary to define the required indicators. Indicators, along with their weights, were collected by a questionnaire from experts and experts and are presented in Table 4.

Table 4

Managers' Performance Evaluation Indicators

\begin{tabular}{llc}
\hline Main Indicator & Sub-index & weight \\
\hline \multirow{4}{*}{ Personal traits } & Open to criticism & .02 \\
& Being law abiding & .27 \\
& Clean appearance & .26 \\
& Observance ethic \& rituals & .24 \\
& Honsty & .25 \\
Technical skill & Transparancy & .26 \\
& Applying modern technologies & .02 \\
& Miritocracy & .02 \\
& Accuracy of action & .02 \\
& Organation and planning & .02 \\
Perceptual skill & Monitoring and controlling & .29 \\
& Organizational commitment & .02 \\
& Dicision making & .02 \\
& Maintaining discipline & .02 \\
& Judgment \& justice & .23 \\
Human skill & Ability to predict concequencies & .02 \\
& Compatibility & .02 \\
& Social responcibility & .02 \\
& Responsivness & .02 \\
& Leadership & .02 \\
& Team building & .02 \\
& Communication & .02 \\
\hline
\end{tabular}

\section{Data Analysis}

In order to rank the primary indices, it must be ensured that there were coordination and relationship between indices using DEMATEL technique (Table 9). This technique is a method of decisionmaking based on paired comparisons (Caligiuri, Joshi, \& Lazarova, 1999), which its results help to apply the analytic network process.

\section{Determining the Relationship between Variables Using DEMATEL Technique}

First stage: Elements constituting the system are the same identified criteria.

Second stage: Using the questionnaire, we asked the experts for the intensity of final relationships. The number of experts who completed the related questionnaire in this section was 15 . As displayed in Table 5, the intensity of the relationships between the leading indicators should be measured by experts, and the results show the impact of each of the criteria on each other which is called the direct relationship matrix. The intensity of the effect of criteria on each other is scaled according to the Likert spectrum so that the amount of zero shows the least, and the amount of four shows the most effect.

Table 5

The Mean of Experts' Opinions about the Effect of Criteria on one another (The Direct Relationship Matrix)

\begin{tabular}{lcccc}
\hline$X$ & Human & Personal & Technical & Perceptual \\
\hline Human skill & 0 & 3 & 3 & 1 \\
Personal traits & 1 & 0 & 1 & 3 \\
Technical skill & 2 & 4 & 0 & 2 \\
Perceptual skill & 1 & 3 & 4 & 0 \\
\hline
\end{tabular}


Third stage: Normalization or scaling is a fundamental concept in multi-criteria decision-making techniques such as AHP and ANP. Standardization in multi-criteria decision-making techniques means scaling and allows data to be compared with different measurement criteria. At this stage, the direct relationship matrix, which was obtained at the previous stage, was normalized. In order to normalize the data, all the entries of the matrix were multiplied by the least inverse value of the sum of the largest row and column values. It was obtained through the following equation:

$$
S=\min \left(\frac{1}{\max (\operatorname{sum}(A * 1))} * 1 / \max (\operatorname{sum}(A * 2))\right)
$$

where $\mathrm{S}$ indicates the overall direct effects of the criterion with the most effects on other criteria and $\mathrm{A}$ is the direct relationship matrix. In the next step, each of the elements of matrix $\mathrm{A}$ was divided into $\mathrm{S}$, and matrix $\mathrm{D}$ was obtained. The results are indicated in Table 6.

Table 6

The Normalized Matrix of the Effect of Criteria on one another (The Normalize Matrix)

\begin{tabular}{lcccc}
\hline $\mathrm{N}$ & Human & Personal & Technical & Perceptual \\
\hline Human skill & .00 & .30 & .30 & .10 \\
Personal traits & .10 & .00 & .10 & .30 \\
Technical skill & .20 & .40 & .00 & .20 \\
Perceptual skill & .10 & .30 & .40 & .00 \\
\hline
\end{tabular}

Fourth stage: The complete relationship matrix (Table9) is obtained through the following phrase.

$$
T=\lim _{k \rightarrow \infty}\left(D^{1}+D^{2}+\cdots+D^{K}\right)=D \times(\mathrm{I}-D)^{-1}
$$

where $\mathrm{I}$ is the identity matrix and $\mathrm{D}$ is the mean of experts' normalized opinions. The results are shown in Table 7.

Table 7

The Complete Relationship Matrix of the Effect of Criteria on one another

\begin{tabular}{lcccc}
\hline $\mathrm{T}$ & Human & Personal & Technical & Perceptual \\
\hline Human skill & .25 & .78 & .65 & .49 \\
Personal traits & .28 & .43 & .44 & .54 \\
Technical skill & .44 & .90 & .46 & .60 \\
Perceptual skill & .39 & .86 & .78 & .45 \\
\hline
\end{tabular}

Fifth stage: Producing a causal diagram. Table 8 shows the degree to which each of the criteria affects each other. The sum of elements in a row (D) for each factor indicates the intensity of affecting other system factors. The sum of elements in column $(\mathrm{R})$ indicates the intensity of being affected by other system factors. Therefore, the horizontal vector $(D+R)$ is the degree of the impact on the system's desired factor. The higher the $\mathrm{D}+\mathrm{R}$ factor, the more it interacts with other system factors. The vertical vector (D - R) indicates the power of effect on each factor. In general, if D - R is positive, the variable is causal variable, and if it is negative, it is affective.

Table 8

The Intensity of Affecting Criteria and Being Affected by Them

\begin{tabular}{lcccc}
\hline & $\mathrm{D}$ & $\mathrm{R}$ & $\mathrm{D}+\mathrm{R}$ & $\mathrm{D}-\mathrm{R}$ \\
\hline Human skill & 2.19 & 1.38 & 3.57 & 0.81 \\
Personal traits & 1.71 & 2.98 & 4.70 & -1.27 \\
Technical skill & 2.42 & 2.35 & 4.77 & 0.06 \\
Perceptual skill & 2.50 & 2.10 & 4.60 & 0.39 \\
\hline
\end{tabular}

Sixth stage: Calculating the relationship threshold. In order to determine Network Relationships Maps (NRM), the value of threshold must be calculated (Table 9). Using this method, minor relationships can be ignored, and considerable relationships are drawn. Only relationships with 
values in the T matrix are higher than the threshold value displayed in the NRM. To calculate the threshold value of the relations, it is sufficient to calculate the T matrix's average values. After the threshold intensity is determined, all matrix $\mathrm{T}$ values that are smaller than the threshold are zero, i.e. the causal relationship is not considered. The threshold for these criteria is .85 (number 1 means that the row factor affects column factor).

Table 9

\begin{tabular}{lcccc}
\multicolumn{4}{l}{ Considerable Relationships between the Primary } & Criteria of the Research (Boxes with Number 1) \\
\hline $\mathrm{T}$ & Human & Personal & Technical & Perceptual \\
\hline Human skill & 1 & & \\
Personal traits & 1 & 1 & \\
Technical skill & & 1 & \\
Perceptual skill & & & \\
\hline
\end{tabular}

\section{Ranking of Native and Non-native Managers Using the TOPSIS Method}

In order to rank native and non-native managers in terms of performance, TOPSIS techniques were applied. In this technique, the factor or alternative is assessed by a person or a group of decisionmaking people. TOPSIS is based on the concept that any selected factor must have the shortest distance with the ideal positive (the most important) factor and the longest distance with the ideal negative (the least important) factor. In other words, in this method, the distance between a particular factor and the ideal positive or negative factor is measured so that factors are graded and prioritized. The results of this technique indicated the better performance of native managers in comparison to non-native managers. The steps of this method are explained below:

\section{Create a decision matrix}

To form a decision matrix, we must first obtain the matrix of pairwise comparisons of factors for each index. To do this, according to experts, we brought the value and importance of each element to other factors in line with the index presented in the square matrix. The principal diameter of this matrix is 1 (the significance of each element relative to itself is 1). In this part of the research, since the pairwise comparison matrix was a 54 x 54 square matrix and it was not possible to display it on the page; We did not put it. Using linear normalization and linear averaging methods, the pairwise comparison matrix is converted into a vector and placed in the columns of the decision matrix.

\section{Create a Pairwise Comparison Matrix to Find the Weights of the Criteria}

To measure the priority of each criterion, we used the pairwise comparison matrix. This means that we used a multi-expert view and put the importance of each criterion in relation to the other criterion in a matrix. The main diameter of this matrix is 1 and it is square. Any element above the main diameter is inversely below the original diameter. By linear normalization and then linear averaging, the weight of each criterion was determined. In this study, the weight of the criterion (impact rate) is equal to 1 .

\section{Normalize the Decision Matrix}

In order to be comparable, the decision matrix is converted to a normalized or unbalanced matrix $\left(N_{1}\right)$ using Equation 1.

$$
\text { Relation 1: } n_{i j}=\frac{r_{i j}}{\sqrt{\sum_{i=1}^{m} r_{i j}^{2}}}
$$


In this equation, (r) are the scores that the indicators have assigned to each of the criteria.

\section{Create a Rhythmic Matrix}

To formulate a rhythmic matrix, each of the normalized matrix columns was multiplied by the weight of that column. In this study, because the criterion weight of the "impact degree" was 1 , the rhythmic matrix and the normalized matrix are the same.

\section{Determining the Ideal Positive Element and the Negative Ideal}

At this stage, the criteria that have been identified as the most important and least important criteria by the respondents should be defined. In other words, for positive indices, the positive ideal is the most significant value of $\mathrm{v}$, and the negative ideal is the smallest value of $\mathrm{v}$, also for negative indicators, the positive ideal is the lowest value of $\mathrm{v}$, and the negative ideal is the most significant value of v. Equation 2 and 3 states this:

Equation 2: Positive Ideal

$$
A^{+}=\left\{\left(\max _{i} V_{i j} \mid j \in J\right),\left(\min _{i} V_{i j} \mid j \in J^{\prime}\right) \mid i=1,2, \ldots, m\right\}=\left\{V_{1}^{+}, V_{2}^{+}, \ldots, V_{n}^{+}\right\}
$$

Equation 3: Positive Ideal

$$
A^{-}=\left\{\left(\min _{i} V_{i j} \mid j \in J\right),\left(\max _{i} V_{i j} \mid j \in J^{\prime}\right) \mid i=1,2, \ldots, m\right\}=\left\{V_{1}^{-}, V_{2}^{-}, \ldots, V_{n}^{-}\right\}
$$

where are $J$ are positive indicators and $J^{\prime}$ are negative indicators.

We considered the most important indicators as positive ideals and the least important indicators as negative ideals as represented in Table 10 .

Table10

Positive and Negative Ideals

\begin{tabular}{lllll}
\hline $\mathbf{+} \mathbf{A}=$ & .06 & .04 & .02 & .09 \\
$\mathbf{- A}=$ & .01 & .00 & .01 & .03 \\
$\mathbf{+}=$ & .00 & .03 & .11 \\
$\mathbf{- A}=$ & .08 & .01 & .00 & .02 \\
\hline
\end{tabular}

\section{Calculate the Distance from the Positive and Negative Ideals}

In this stage, the distance between each of the options from positive and negative ideals was determined according to the equation 4 and 5 .

Equation 4: The distance between the options and the positive ideal

$$
d_{i}^{+}=\sqrt{\sum_{j=1}^{n}\left(V_{i j}-V_{j}^{+}\right)^{2}} ; i=1,2, \ldots, m
$$

Equation 5: The distance between the options and the negative ideal

$$
d_{i}^{-}=\sqrt{\sum_{j=1}^{n}\left(V_{i j}-V_{j}^{-}\right)^{2}} ; i=1,2, \ldots, m
$$




\section{Calculate the Degree of Proximity of Each Factor to the Positive Ideal Factor and the Negative Ideal}

In this stage, the degree of proximity of each indicator to positive and negative ideals ( $C L$ ) was calculated according to the equation 6 .

Equation 6: Calculate the proximity of indicators to ideal factors

$$
C L_{i}=\frac{d_{i}^{-}}{d_{i}^{-}+d_{i}^{+}}
$$

At this stage, the options are ranked by value. In other words, any higher option will get a better rating because it is farther from the negative ideal and closer to the positive ideal. Table 11 shows the ranking of options. Note that the classification of options is in order from least impact to highest impact because we have considered the criterion of "impact rate" as a negative criterion.

Table 11

\begin{tabular}{|c|c|c|c|c|c|c|c|c|}
\hline Rank & $\begin{array}{l}\text { Type of } \\
\text { manager }\end{array}$ & $\begin{array}{c}\text { CL } \\
\text { value }\end{array}$ & Rank & $\begin{array}{l}\text { Type of } \\
\text { manager }\end{array}$ & $\begin{array}{c}\text { CL } \\
\text { value }\end{array}$ & Rank & $\begin{array}{l}\text { Type of } \\
\text { manager }\end{array}$ & $\begin{array}{c}\mathrm{CL} \\
\text { value }\end{array}$ \\
\hline 1 & Native & 1 & 19 & Native & .75 & 37 & Native & .53 \\
\hline 2 & Native & 1 & 20 & Non-native & .75 & 39 & Non-native & .52 \\
\hline 3 & Non-native & 1 & 21 & Non-native & .73 & 39 & Native & .51 \\
\hline 4 & Native & 1 & 22 & Non-native & .73 & 40 & Non-native & .51 \\
\hline 5 & Native & 1 & 23 & Native & .72 & 41 & Non-native & .51 \\
\hline 6 & Native & .85 & 24 & Native & .72 & 42 & Non-native & .49 \\
\hline 7 & Native & .82 & 25 & Native & .71 & 43 & Native & .46 \\
\hline 8 & Native & .82 & 26 & Native & .69 & 44 & Native & .46 \\
\hline 9 & Native & .82 & 27 & Native & .69 & 45 & Non-native & .40 \\
\hline 10 & Non-native & .81 & 28 & Non-native & .66 & 46 & Native & .39 \\
\hline 11 & Native & .81 & 29 & Native & .66 & 47 & Native & .34 \\
\hline 12 & Native & .81 & 30 & Native & .66 & 48 & Non-native & .33 \\
\hline 13 & Native & .80 & 31 & Non-native & .64 & 49 & Native & .32 \\
\hline 14 & Native & .80 & 32 & Native & .60 & 50 & Non-native & .20 \\
\hline 15 & Native & .8 & 33 & Native & .60 & 51 & Non-native & .17 \\
\hline 16 & Native & .78 & 34 & Native & .57 & 52 & Non-native & .16 \\
\hline 17 & Native & .77 & 35 & Native & .54 & 53 & Native & .14 \\
\hline 18 & Native & .75 & 36 & Native & .53 & 54 & Native & .11 \\
\hline
\end{tabular}

Finally, we attempted to collect and analyze the data in order to rank the primary concepts of each native and non-native manager of the research using common techniques such as DEMATEL technique and ANP which are compatible with the methodology and type of variables. Super Decisions software was also applied, which its results are listed in Table 12 and 13. The inconsistency rate is equal to .000 , which is smaller than the standard level of .1; thus, the questionnaire has been completed with high accuracy by the respondents. Research shows that the beneficiaries' perceptions of managers are not the same and can be defined based on four leading indicators and the high correlation coefficient to evaluate managers' performance. Other significant results can be mentioned.

Table 12

Ranking the Primary Indices of Native Managers' Performance

\begin{tabular}{cccc}
\hline Number & Criterion & Weight & Ranking \\
\hline 1 & Perceptual skill & .29 & 2 \\
2 & Human skill & .19 & 3 \\
3 & Technical skill & .11 & 4 \\
4 & Personal trait & .38 & 1 \\
\hline
\end{tabular}


Table 13

Ranking the Primary Indices of Non-native Managers' Performance

\begin{tabular}{cccc}
\hline Number & Criterion & Weight & Ranking \\
1 & Personal trait & .28 & 2 \\
2 & Technical skill & .11 & 4 \\
3 & Perceptual skill & .21 & 3 \\
4 & Human skill & .34 & 1 \\
\hline
\end{tabular}

\section{Discussion and Conclusion}

By using performance appraisal models and mathematical decision-making models, it is possible to evaluate and rank the organization's employees. The combination of two 360-degree evaluation techniques and TOPSIS multi-criteria decision models leads to the least error and thus the application of the results in senior organizational managers' decisions. By performing statistical analysis with SPSS software and calculating Cronbach's alpha correlation between sub-indices and leading indices, it proves a high correlation between sub-indices. Other remarkable results include: the total weight of the opinions of the subordinate evaluators and the person being evaluated is approximately equal to the weight of the superior opinions; the total weight of the peer evaluators' opinions and the evaluated person is almost more than the weight of the superior views; the total weight of the opinions of the peer and subordinate evaluators is more than the weight of the superior opinions. Also, using the network analysis process, it was possible to calculate weight of each of the leading indicators, which shows the degree of sensitivity and impact on the performance of managers.

According to the results of statistical analysis, the component of personal traits is the top priority for assessing native managers' performance. Perceptual skill and human skill are respectively ranked second and third, and the component of technical skill is ranked last in assessing native managers' performance. Perhaps the essential cause for the weakness of this component lies in the gap between the existed level and the desired and expected level of the fourth plan formulated for the general policies of the administrative system. In order to reach the desired level, required infrastructures and mechanisms to form the electronic government and single window must be provided with the help of managers to develop business and administrative activities and create systems of clarifying the activities of the governmental centre. In ranking the components of assessing non-native managers' performance, human skill is ranked first with the most significant weight and personal traits, perceptual skill, and technical skill are ranked second, third, and fourth respectively. In analyzing the latter components of assessing non-native managers' performance, it can be stated that technical skill is the joint shortcoming of native and non-native managers' performance. If this matter is handled friendly and constructively based on cooperation rather than competitiveness and independence-seeking, it can lead to organizational growth and commitment as well as innovation and affect native and non-native managers' performance positively (Bhagwat \& Sharma, 2007).

Furthermore, the technical and functional aspects of managers in the innovative atmosphere of the organization can mature. Regarding perceptual skill, the cultural incompatibility is considered the most critical characteristic of undesirability in multi-cultural environments (Caligiuri, 2000). Facing new cultural components by non-native people is considered to be a culture shock as a multidimensional phenomenon of confronting the mental pressures of the environment (Gunasekaran \& Kobu, 2007). Since they cannot adapt these cultural components to the socio-cultural exchange symbols of their birthplace, they experience unpleasant emotions such as helplessness and role 
confusion (Spekle \& Verbeeten, 2009). Non-native managers work in environments where their infrastructural assumptions are different from the place they have grown up. These managers require a cooperative approach presented by the host culture, which is different from their own culture. Thus, for more productivity, they require an approach related to the principles of cultural intelligence. For example, according to Hofstede's (2010) theory, there are significant differences between underlying cultural assumptions and behavioural values dominating managers in different sections and they are usually regarded as common misunderstandings between managers and employees of different cultures. Lack of control over the cultural basics and values of the workplace can cause culture shock. In order to meet this cultural challenge, non-native managers must increase their cultural knowledge, and by gaining cultural experience over the time, they can overcome the cultural complications of the environment and exhibit more acceptable behaviour towards other people.

Finally, some suggested research is presented: 1. In this study, only the opinions of four groups of beneficiaries were surveyed. Other beneficiaries, including ex co-workers, customers, employers, friends, family, etc., can be considered, and the method can be developed, 2. Applying other multi-criteria decision-making techniques such as Vicor, Savo, and Electr, etc. with a 360degree measuring method to evaluate and rank employees can be useful, and 3. It is suggested that other skills, such as strategic skills and psychological skills of work as a general concept not categorized in this study, to be discussed in other studies.

\section{References}

Aschbacher, P. R., \& Herman, J. (1991). Final report of the Humanitas program evaluation. Los Angeles: University of California.

Asgharizadeh, E., Ehsani, R., \& Valipour, F. (2012). Assessing managers' performance using 360-degree feedback and VIKOR method (Case study: Engineering Research Center of Agricultural Organization). Studies of Industrial Management, 9(23), 2148.

Bhagwat, R., \& Sharma, M. K. (2007). Performance measurement of supply chain management: A balanced scorecard approach. Computers and Industrial Engineering, 53(1), 43-62.

Bititci, U. S., Garengo, P., Dörfler, V., \& Nudurupati, S. (2012). Performance measurement: Challenges for tomorrow. International Journal of Management Reviews, 14(3), 305-327.

Brown, R., \& Pehrson, S. (2019). Group processes: Dynamics within and between groups. John Wiley \& Sons.

Brugal, M. P., Ballesta, R. G., Bravo, M. P., Barrio, G. A., Domingo, A. S., do Rosario Silva, T., \& Ambrós, M. H. (2005). Cohort study methodology of the ITINERE Project on heroin users in three Spanish cities and main characteristics of the participants. URevista Espanola de Salud Publica, U79(4), 475-491.

Caligiuri, P. M. (2000). Selecting expatriates for personality characteristics: A moderating effect of personality on the relationship between host national contact and cross-cultural adjustment. Management International Review, 40, 61-80.

Caligiuri, P. M., Joshi, A., \& Lazarova, M. (1999). Factors influencing the adjustment of women on global assignments. The International Journal of Human Resource Management, 10(2), 163-179.

Cavalluzzo, K. S., \& Ittner, C. D. (2003). Implementing performance measurement innovations: Evidence from government. Accounting, Organizations, and Society, 29(3-4), 243-267.

de Andrés, R., García-Lapresta, J. L., \& Martínez, L. (2010). A multi-granular linguistic model for management decision-making in performance appraisal. Soft Computing, 14(1), 21-34.

Folan, P., \& Browne, J. (2005). A review of performance measurement: Towards performance management. Computers in Industry, 56(7), 663-680.

Franco-Santos, M., Lucianetti, L., \& Bourne, M. (2012). Contemporary performance measurement systems: A review of their consequences and a framework for research. Management Accounting Research, 23(2), 79-119.

Gunasekaran, A., \& Kobu, B. (2007). Performance measures and metrics in logistics and supply chain management: A review of recent literature (1995-2004) for research and applications. International Journal of Production Research, 45(12), $2819-2840$. 
Halachmi, A. (1999). Mandated performance measurement: A help or a hindrance? National Productivity Review, 18(2), 59-67.

Hall, M. (2008). The effect of comprehensive performance measurement systems on role clarity, psychological empowerment, and managerial performance. Accounting, Organizations, and Society, 33(2-3), 141-163

Heinrich, C. (2002). Outcomes-based performance management in the public sector: Implications for government accountability and effectiveness. Public Administration Review, 62(6), 712-725.

Henri, J. F. (2006). Organizational culture and performance measurement systems. Accounting, Organizations, and Society, 31(1), $77-103$.

Hofstede, G. (2010). Geert hofstede. National cultural dimensions, 2-7.

Huang, G., Tong, Y., Ye, F., \& Li, J. (2019). Extending social responsibility to small and medium-sized suppliers in supply chains: A fuzzy-set qualitative comparative analysis. Applied Soft Computing, 88, 105899.

Jafari, M., Bourouni, A., \& Amiri, R. H. (2009). A new framework for selection of the best performance appraisal method. European Journal of Social Sciences, 7(3), 92-100.

Kelly, J. (2012). Rethinking industrial relations: Mobilisation, collectivism and long waves. Routledge.

Kim, B., \& Oh, H. (2002). An effective R\&D performance measurement system: Survey of Korean R\&D researchers. Omega, $30(1), 19-31$.

Kloot, L., \& Martin, J. (2000). Strategic performance management: A balanced approach to performance management issues in local government. Management Accounting Research, 11(2), 231-251.

Krishna, D., Mohan, S. R., Murthy, B. S. N., \& Rao, A. R. (2002). Performance evaluation of public research institutes using principal component analysis. JSIR, 61(11), 940-947.

Lawler, E. E. (1967). The multitrait-multirater approach to measuring managerial job performance. Journal of Applied Psychology, 51(5), 369-381.

Melnyk, S. A., Bititci, U., Platts, K., Tobias, J., \& Andersen, B. (2014). Is performance measurement and management fit for the future? Management Accounting Research, 25(2), 173-186.

Mikolajczyk, K., \& Schmid, C. (2005). A performance evaluation of local descriptors. IEEE Transactions on Pattern Analysis and Machine Intelligence, 27(10), 1615-1630.

Modell, S. (2001). Performance measurement and institutional processes: A study of managerial responses to public sector reform. Management Accounting Research, 12(4), 437-464.

Moxham, C. (2009). Performance measurement: Examining the applicability of the existing body of knowledge to nonprofit organizations. International Journal of Operations and Production Management, 29(7), 740-763.

Moynihan, D. P., \& Pandey, S. K. (2005). Testing how management matters in an era of government by performance management. Journal of Public Administration Research and Theory, 15(3), 421-439.

Rienties, B., Beausaert, S., Grohnert, T., Niemantsverdriet, S., \& Kommers, P. (2012). Understanding academic performance of international students: The role of ethnicity, academic and social integration. Higher Education, 63(6), 685-700.

Sanderson, I. (2002). Performance management, evaluation, and learning in 'modern' local government. Public Administration, 79(2), 297-313.

Sharifi, A. (2010). The components of management and efficiency of government in Alavipractical behaviour (Unpublished master's thesis). Islamic Azad University, Central Tehran Branch, Iran.

Sharma, M. K., Bhagwat, R., \& Dangayach, G. S. (2005). Practice of performance measurement: Experience from Indian SMEs. International Journal of Globalization and Small Business, 1(2), 183-213.

Smith, R. A., \& Khawaja, N. G. (2011). A review of the acculturation experiences of international students. International Journal of Intercultural Relations, 35(6), 699-713.

Spekle, R. F., \& Verbeeten, F. H. M. (2009). The use of performance measurement systems in the public sector: Effects on performance. Management Accounting Research, 25(2), 131-146.

Takagi, H. (1991). Queueing analysis: a foundation of performance evaluation (Vol. 1). Amsterdam: North-Holland.

Taylor, F. A., Ketcham, A. F., \& Hoffman, D. (1990). Personnel evaluation with AHP. Management Decision, 36(10), 679-685.

Tangen, S. (2004). Performance measurement: From philosophy to practice. International Journal of Productivity and Performance Management, 53(8), 726-737.

Tripathy, S., Ray, P. K., \& Sahu, S. K. (2011). Performance measurement of R\&D is a vaccine for innovation capability: Evidence from Indian manufacturing organizations. International Journal of Electronic Transport, 1(1), 76-95.

Verbeeten, F. H. M. (2008). Performance management practices in public sector organizations. Accounting, Auditing, and Accountability Journal, 21(3), 427-454. 
Wang, G., Oh, I. S., Courtright, S. H., \& Colbert, A. E. (2011). Transformational leadership and performance across criteria and levels: A meta-analytic review of 25 years of research. Group \& Organization Management,36(2), 223-270.

Ward, C. A., Bochner, S., \& Furnham, A. (2001). The psychology of culture shock. Psychology Press.

Ward, C., \& Kennedy, A. (2001). The measurement of sociocultural adaptation. International Journal of Intercultural Relations, 23(4), 659-677.

Zhou, Y., Jindal-Snape, D., Topping, K., \& Todman, J. (2008). Theoretical models of culture shock and adaptation in international students in higher education. Studies in Higher Education, 33(1), 63-75. 